\title{
As Transformacões Urbanas e a Sazonalidade: Produtores do Conforto Térmico do Centro da Cidade de Sabral-CE
}

\section{Urban transformations and the seasonality: producers of the thermal comfort from the Sobral- CE}

Francisco Gerson Lima Muniz * Isorlanda Caracristi **

\section{Resumo:}

A presente pesquisa tem como objetivo demonstrar a relação entre a urbanização e as alterações microclimáticas na cidade de Sobral (CE) e como o processo atual de crescimento da cidade, num contexto ambiental de semiaridez, pode interferir no conforto térmico. A metodologia utilizada na pesquisa fundamentou-se no "Sistema Clima Urbano" (SCU), de Carlos Augusto Monteiro (2003), na perspectiva do canal I, termodinâmico. A coleta de dados foi realizada em dois experimentos de períodos sazonais contrastantes, com medições simultâneas realizadas nos horários de 6, 9, 12, 15 e 18 horas. Os resultados encontrados evidenciam que os elementos paisagísticos urbanos favorecem para a formação de atributos microclimáticos desfavorávies ao conforto térmico, sobretudo no período seco da cidade.

Abstract:

This present research has as an objective to demonstrate the relationship between the urbanization and the microclimatic changes in the city of Sobral (CE) and how the present process of growth in an environmental context of semiarid can interfere on the thermal comfort. The methodology used on the search were based on "System of Urban Climate", of Carlos Augusto Monteiro (2003), on the perspective of Channel I, thermodynamic. The data collection was made in two experiments of contrasting seasonal period, with simultaneous measurements made on the time of 6 a.m., 9 a.m., 12 p.m., 3 p.m., and 6 p.m. The results evidence that the landscaped elements favor to the formation of microclimatic attributes unfavorable to thermal comfort especially in the dry season of the city.
MSc. em Geografia pela Universidade Estadual Vale do Acaraú. Professor Efetivo da rede pública de Ensino do Estado do Ceará

** Doutora em Geografia Física pela Universidade de São Paulo. Professora adjunta da Universidade Estadual Vale do Acaraú (UVA). 


\section{INTRODUÇÃO}

s climas globais receberam grande atenção
por parte dos estudiosos e da mídia em relação aos outros problemas ambientais, tendo em vista que a temperatura é o principal elemento que afeta diretamente a sensação/percepção ambiental, principalmente quando se trata de ambientes urbanos. Nesta ótica, a tese desenvolvida por Carlos Augusto de F. Monteiro em 1975/1976, intitulada Teoria e clima urbano, significou uma verdadeira reformulação aos trabalhos de fins climatológicos na perspectiva geográfica e em contexto nacional.

Em sua teoria, Monteiro afirma que, sendo a cidade a "moradia do homem", todas as suas relações de organização, edificação, funções e serviços estavam arquitetados em uma estrutura morfológica, características geoecológicas e dinâmica climática própria, culminando num Sistema Clima Urbano - S.C.U. (MONTEIRO, 2003), que se constitui no referencial metodológico utilizado nesta pesquisa, principalmente as bases conceituais referentes aos sistemas de percepção do Canal I, termodinâmico.

O canal de percepção do conforto térmico ou termodinâmica engloba as componentes derivadas do calor, da ventilação e umidade e afeta a todos de forma irrestrita e constante, com menos ou maior intensidade. As pesquisas no campo termodinâmico têm tido grande crescimento e aplicação, pois tratam de parâmetros que se relacionam diretamente com o conforto ambiental e qualidade de vida humanos.

As componentes termodinâmicas do clima (canal I) não só conduzem ao referencial básico para ação do conforto térmico urbano como são, antes de tudo, a constituição do nível fundamental de resolução climática para onde convergem e se associam todas outras componentes.Dentro do esquema do S.C.U., esse canal atravessa toda a sua estrutura, pois que é o insumo básico, é transformado na cidade e pressupõe uma produção fundamental no balanço de energia líquida atuante no sistema. O uso do solo, a morfologia urbana, bem como suas funções, estão intimamente implicados no processo de transformação e produção (MONTEIRO, 2003, p. 44).

Para entendimento da atuação dos elementos do clima no conforto térmico, Souza e Nery (2012) citam Pagnossin, Buriol e Graciolli (2001):

[...] O conforto térmico exprime satisfação com o ambiente térmico, sendo vários fatores que influenciam, entre eles os aspectos físicos relacionados aos processos de trocas de calor: condução, convecção, radiação e evaporação que ocasionam no organismo ganhos e perdas de energia com o meio, através da influência das variáveis meteorológicas como a temperatura, umidade, movimento do ar e radiação responsáveis por uma maior ou menor sensação de conforto térmico[...](SOUZA e NERY, 2012, p. 71).

As transformações ocorridas à medida que a urbanização avança nas cidades, geram uma série de impactos ambientais, perceptíveis principalmente pelos citadinos, "que começam a sentir os efeitos do ambiente construído, sob a forma de acúmulo de calor, dificuldade de dispersão da poluição, ocorrências de inundações" (FREITAS, 2005 p. 17). O processo de transição entre uma paisagem natural para uma paisagem humanizada representa numa reconfiguração do ecossistema natural, e um dos elementos chaves nesta reconfiguração é o clima, e uma vez alterado seu padrão há resultados significantes dentro desse ecossistema, principalmente quando se trata de urbanização.

É na cidade que as transformações no ambiente são mais significativas, pois a urbanização evidencia com maior clareza as modificações atmosféricas, tanto que Monteiro (1990a) indica a necessidade de um maior número de estudos sobre o clima urbano.

O município de Sobral, onde se situa a área específica da presente pesquisa, está inserido na Região Noroeste do Estado do Ceará (mapa 1), distante aproximadamente $230 \mathrm{~km}$ da capital Fortaleza por via rodoviária. Está localizado em torno das coordenadas de $3^{\circ} 41^{\prime} 10^{\prime}$ de latitude (S) e 40 20'59" de longitude (WGr) e possui altimetria média de $70 \mathrm{~m}$. O município é formado por 17 distritos, incluindo o Distrito-Sede e tem como extensão territorial uma área de $2.123 \mathrm{Km}^{2}$, equivalente a $1,43 \%$ do território estadual

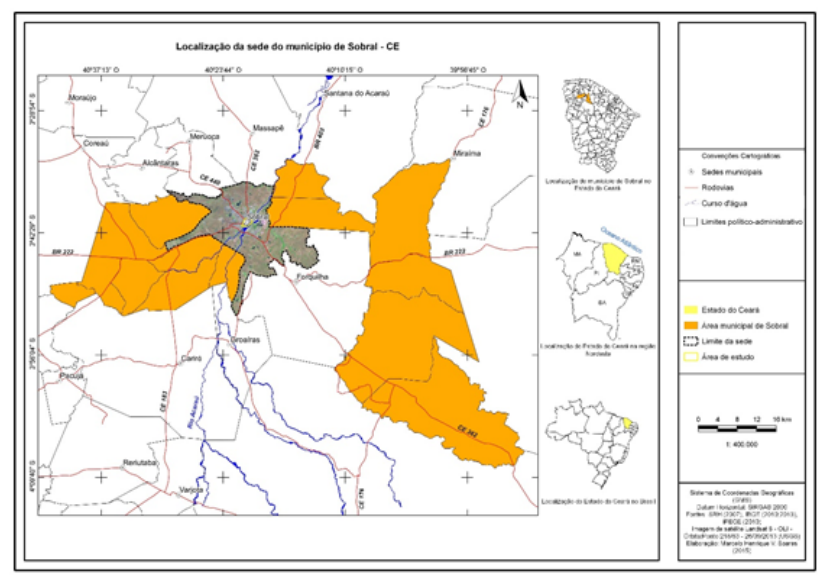

Mapa 1 - Localização do município de Sobral Fonte: MUNIZ, F.G.L, 2016 
Nesse contexto, nosso objetivo geral foi constituído em: Demonstrar cientificamente a relação entre a urbanização e as alterações microclimáticas no centro da cidade de Sobral (CE) e como o processo atual de crescimento da cidade, num contexto ambiental de semiaridez, pode interferir no conforto térmico. Como buscas específicas tivemos: Estudar as diferenças microclimáticas dos espaços do bairro central da cidade de Sobral por meio da análise dos parâmetros dos elementos do clima (temperatura, pluviosidade, vento e umidade relativa do ar) em período acentuado de semiaridez e outro no período de pluviosidade na região. Verificar a relação entre as alterações nos parâmetros climáticos (temperatura, pluviosidade, vento e umidade relativa do ar) sobre o conforto térmico nos espaços em estudo.

A cidade de Sobral se localiza na Região do Semiárido do Nordeste Brasileiro, onde as altas temperaturas e os baixos índices pluviométricos anuais, condicionam a dinâmica social e ambiental. Tal aspecto aliado aos processos históricos de uso e ocupação, onde o desmatamento sempre prevaleceu, faz com que desenvolver estudos climáticos na escala da vivência cotidiana humana, assuma caráter de grande relevância para recuperação e manutenção da melhoria da qualidade socioambiental. Fato que vem motivando os pesquisadores do Curso de Geografia da Universidade Estadual Vale do Acaraú (UEVA), mas precisamente do Laboratório de Estudos Ambientais (LEA), a se dedicarem na produção de banco de dados sobre o clima da Região do Médio Curso do Rio Acaraú.

Para abranger esta discussão o artigo foi organizado em 4 tópicos, além das considerações finais. O primeiro, a introdução, diz respeito ao presente tópico composto pelos questionamentos, objetivos da pesquisa, além da localização geográfica da área em estudo. O segundo tópico trata sobre o contexto socioambiental da cidade de Sobral, o terceiro tópico, traz os procedimentos metodológicos, e o quarto e último, os resultados e discussões.

\section{SOBRAL EM SEU CONTEXTO SOCIOAM- BIENTAL}

A cidade de Sobral teve seu surgimento e crescimento ligado ao Rio Acaraú e este processo sempre ocorreu em forma de exploração extensiva do solo e desmatamento, atingindo seus afluentes e sub-bacias. $\mathrm{Na}$ cultura popular isso é perceptível, pois as comunidades ribeirinhas têm suas casas com os fundos para o rio, fazendo-o de esgoto e lugar de despejo de lixo. $\mathrm{O}$ atual estágio de poluição das águas do sistema fluvial da cidade é grave (figura 01), ampliando-se às comunidades à jusante, que são afetadas pela poluição e alterações ambientais induzidas pela população de Sobral.

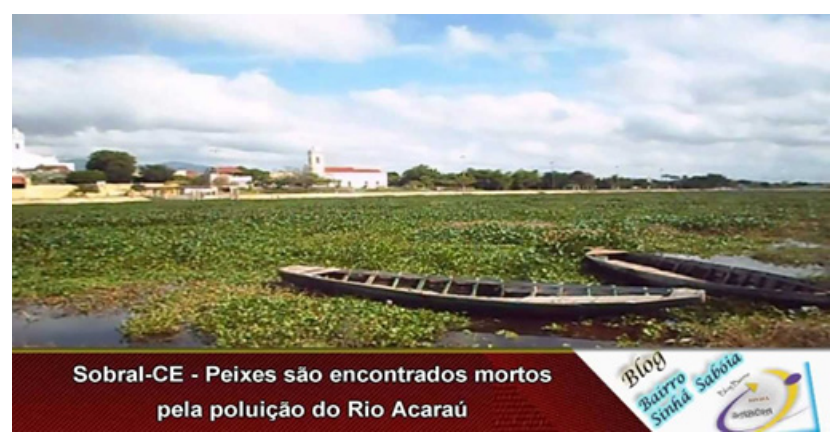

Figura 01 - Repotagem sobre a Poluição do Rio Acaráu Fonte: http://blogsinhasaboia.blogspot.com.br (2016)

Dois fatos marcam a história de Sobral na década de 1990, a chegada da empresa Grendene e a primeira gestão municipal de Cid Gomes (1997-2000). Esses fatos tiveram significados profundos na configuração atual da cidade. A chegada da referida empresa tem peso significativo para população, gerando milhares de empregos, atualmente em torno de 23 mil funcionários oriundos de Sobral e cidades adjacentes, e aumento expressivo de receitas, significando um superávit na economia do município (LIMA, 2014).

Já a gestão municipal de Cid Gomes é considerada um marco para cidade pelo modelo de "modernização" adotado inclusive no slogan do segundo mandato (20012004) "Sobral - pronta para o futuro", no intuito de crescimento econômico, através da venda de uma "paisagem moderna" para agregar novos investimentos externo, sobre este tema Sanchéz (2003) explica:

O citymarketing e os planos estratégicos de cidade aparecem como importantes instrumentos do chamado do "novo planejamento urbano" que busca recuperar sua legitimidade quanto à intervenção pública na perspectiva de "colocar as cidades no novo mapa do mundo”. (SANCHÉZ, 2003, p. 25).

Desta forma Holanda (2005) explica tal situação em relação à cidade de Sobral e o citymarketing:

O uso do espaço urbano de Sobral pensado e efetivado pelo prefeito Cid Gomes em duas gestões seguidas (1997/20002001/2004), foi assegurado pelo forte discurso de modernização, com maciços investimentos em infraestrutura e realocação de alguns serviços públicos, que garantissem sucesso nas novas territorializações dos investidores privados. Assim vem ocorrendo um aumento da fluidez, com crescente surgimento de modernos e diferentes tipos de empreendimentos em outros bairros além Centro. (HOLANDA, 2005, p. 229). 
Esse modelo de gestão persiste até os dias atuais (ano de 2017), mesmo que seja em menor escala, tendo em vista que os prefeitos seguintes pertencem ao mesmo grupo político. Ao longo dessas duas décadas a cidade foi recebendo aparatos urbanos que modificaram e ampliaram os negócios e seu potencial estrutural e econômico, assumindo características de cidade média.

O ritmo de crescimento acelerado expandiu a economia de forma positiva, porém motivou negativamente uma especulação imobiliária predatória, produtora direta e indiretamente de vários problemas socioambientais, mesmo com a criação de um órgão para cuidar do desenvolvimento urbano e meio ambiente, a Autarquia Municipal do Meio Ambiente (AMMA) e uma Secretaria Municipal de Desenvolvimento Urbano e Meio Ambiente (SDUMA).

E infelizmente a participação do poder público não se limita apenas à negligência nas fiscalizações, mas também por ser um agente ativo nas modificações das paisagens, sobretudo com obras que transmitem ares de modernização, fortalecendo o projeto político de "venda" da cidade para investidores externos. Os impactos nos sistemas ambientais urbanos são perceptíveis (vide figuras 02 e 03), incluindo o sistema climático, pricipalmente no que se refere ao aumento do desconforto térmico. Pecepção que motivou o desenvolvimento da presente investigação.

Ao investigar o clima urbano, especialmente quando se tem por base o S.C.U. (MONTEIRO, 2003), é imprescindível a caracterização do "natural" do sítio urbano, não apenas de caráter primitivo, é preciso considerar todas as alterações e adequações realizadas de caráter antrópico.

A cidade de Sobral na maior parte do seu território se insere na zona geomorfologicamente deno-

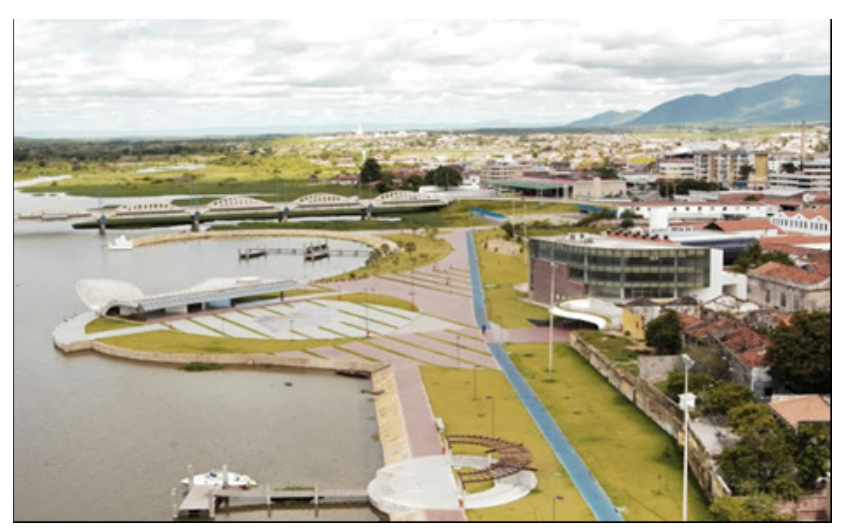

Figura 02 - Margem Esquerda do rio Acaraú posterior à sua urbanização Fonte: http://sobralemboatos.blogspot.com.br (2016)

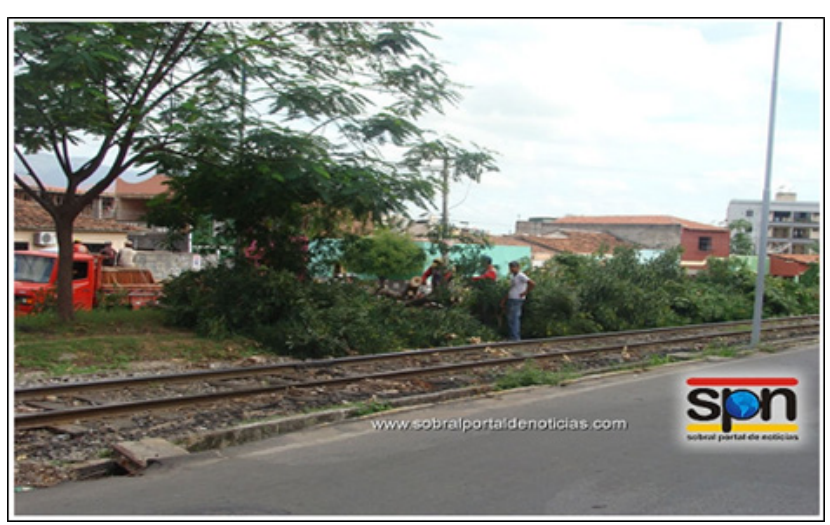

Figura 03 - Desmatamento de mais de 50 árvores efetuados pela prefeitura no perímetro urbano de Sobral, para a implantação do VLT Fonte: Rocha (2013)

minada Depressão Sertaneja, contudo outras unidades morfoculturais são detectadas, como a planície do rio Acaraú e o Maciço Residual Meruoca-Rosário.

Assentada sobre substrato rochoso cristalino, predomina o intemperismo físico, devido aos baixos índices pluviométricos e às altas temperaturas diurnas. Os processos erosivos aliados ao desmatamento da $\mathrm{Ca}$ atinga, bioma regional, têm causado graves problemas à dinâmica hidroclimática intrarregional, aumentando assim a fragilidade ambiental e sua vulnerabilidade aos processos de desertificação.

Sua localização latitudinal encontra-se na faixa climática tropical, região que é caracterizada com a maior incidência dos raios solares, caracterizando-se pelo clima semiárido com duas estações bem definidas, chuvosa (verão/outono) e seca (primavera/inverno). Porém, as chuvas sazonais regulares estão condicionadas principalmente à dinâmica da Zona de Convergência Intertropical - ZCIT (CARACRISTI, 2000).

Conforme a classificação de Köppen e Gaussen citado por Caracristi (2000) os tipos climáticos são BSw'h e 4aTh, respectivamente: clima quente e semiárido de seca acentuada, com déficit hídrico de 7 a 8 meses, estabelecendo assim a sazonalidade de período chuvoso e período seco.

Para a Fundação Cearense de Meteorologia e Recurso Hídricos (FUNCEME) a classificação climática é assim estabelecida:

Tabela 01 - Aspectos Climáticos

\begin{tabular}{|c|c|c|c|}
\hline Clima & $\begin{array}{l}\text { Pluvio- } \\
\text { sidade }\end{array}$ & $\begin{array}{l}\text { Temperatura } \\
\text { média }\left(\mathbf{C}^{\circ}\right)\end{array}$ & $\begin{array}{l}\text { Período } \\
\text { chuvoso }\end{array}$ \\
\hline $\begin{array}{l}\text { Tropical Quente Semi-árido e } \\
\text { Tropical Quente Semi-árido Brando }\end{array}$ & $\begin{array}{l}821,6 \\
\mathrm{~mm}\end{array}$ & $26^{\circ}$ a $28^{\circ}$ & $\begin{array}{c}\text { Janeiro a } \\
\text { maio }\end{array}$ \\
\hline
\end{tabular}

Fonte: Sobral (2010) 
A tabela acima nos mostra os tipos climáticos e alguns atributos referentes ao município de Sobral, sendo: Clima Tropical Quente semiárido e Tropical Quente Semiárido Brando. A sazonalidade pluvial varia entre 3 e 5 meses concentrados no primeiro semestre. A média das amplitudes térmicas anuais é baixa, porém a média diária chega a $5^{\circ} \mathrm{C}$ de diferença entre a máxima (diurna) e a mínima (noturna) em média. As médias das temperaturas máximas anuais chegam a $36^{\circ} \mathrm{C}$, enquanto as mínimas a $24^{\circ} \mathrm{C}$, conforme os dados do INMET.

De acordo com a FUNCEME, a classificação em clima semiárido para cidade de Sobral, e as demais do Ceará, está baseada no cálculo de aridez, obtendo o balanço hídrico através das precipitações e índice de evaporação. $\mathrm{Na}$ cidade de Sobral a média pluviométrica, também segundo a FUNCEME, é de $889,7 \mathrm{~mm} /$ ano, e já o índice de evapotranspiração é de 1951,1mm/ano, ou seja, um balanço hídrico bastante deficitário.

A serra Meruoca, popularmente como é conhecido o maciço, ainda desempenha uma função de indução de brisas, "devido ao aquecimento diferenciado ao longo do dia entre a serra e o vale, é gerado um sistema de brisas semelhante ao mecanismo das brisas litorâneas." (CARACRISTI, 2000, p.06). Ainda segundo a autora serra da Meruoca atua como:

Indutora de chuvas - os ventos esbarram, ascendem e o vapor d'água contido é condensado, possibilitando a ocorrência de chuvas orográficas. (Caracristi, 2000, p. 07).

Enquanto o vale do rio Acaraú, que atua como:

- Canal de ventos litoral - sertão e serra - vale;

- Fonte de umidade atmosférica;

- Amenizador das altas temperaturas locais - devido ao aquecimento diferenciado ao longo do dia entre o rio (água) e a planície de inundação e interflúvio (terra), é gerado um outro sistema de brisas (que se integra ao sistema serra - vale), facilitando as trocas de calor. (Caracristi, 2000, p. 07)

Como podemos perceber estas feições morfológicas tem grande influencia na formação do clima local, seja na distribuição de umidade atmosférica, seja pelo transporte dos ventos Alísios que adentra continente. Segundo Caracristi (2000, p.08) "no Nordeste do Brasil o regime de vento e fortemente condicionado pela circulação em macroescala dos ventos alísios." Entretanto, o comportamento desses ventos é afetado pela presença dos continentes e de suas particularidades climáticas e orográficas.
A partir do acima exposto e considerando os ainda recentes estudos climáticos voltados à escala local na área em análise, ressalta-se a importância da relação entre clima, degradação ambiental e crescimento urbano. $O$ estudo do conforto térmico se insere nessa relação e possui grandes possibilidades de aplicação voltadas à melhoria da qualidade vida dos moradores da cidade. Fato que expõe a relevância social do estudo em questão, principalmente por se tratar de um contexto ambiental de semiaridez.

\section{PROCEDIMENTOS METODOLÓGICOS}

Os pressupostos teórico-metodológicos do S.C.U. de Monteiro (2003), mais precisamente àqueles referentes ao Subsistema Termodinâmico, canal de conforto térmico, foram associados à técnica do Diagrama do Conforto Térmico utilizado pelo Instituto Nacional de Meteorologia - INMET (2013).

Segundo o INMET (2013), no ano de 1987 a Organização Meteorológica Mundial (OMM) estabeleceu os parâmetros meteorológicos relacionados ao conforto térmico humano, considerando as seguintes faixas: umidade, variando de $30 \%$ a $80 \%$; temperatura entre $8,0^{\circ} \mathrm{C}$ e $33,0^{\circ} \mathrm{C}$, observando a importância da radiação entre $8^{\circ} \mathrm{C}$ e $20^{\circ} \mathrm{C}$. Associando-se a tais parâmetros o papel da ventilação no intervalo de temperatura $26^{\circ} \mathrm{C}$ a $34^{\circ} \mathrm{C}$. Esses parâmetros foram utilizados para criação da Diagrama do Conforto Térmico do INMET.

Dentre os vários índices, tabelas e proposições técnicas para o cálculo e análise do conforto térmico, adotou-se o Diagrama utilizado pelo INMET, por ser bastante adequado às condições climáticas de semiaridez, pois ao se inserir os dados, obtém-se uma visualização gráfica muito próxima das reais sensações térmicas da população local, além de sua fácil aplicação.

Os valores de temperatura e umidade próximos às preferências térmicas da população de áreas tropicais, tem sido um motivo para utilização do diagrama do INMET para analisar o conforto térmico em todas as regiões do Brasil.

O levantamento bibliográfico foi realizado com o intuito de aprofundar os conhecimentos dos conceitos centrais da pesquisa, principalmente sobre o conforto térmico do Sistema Clima Urbano de Monteiro (2003). Outras bibliografias, no que concerne ao estudo do clima urbano de diversas regiões, em destaque os trabalhos de cunho estadual com temáticas semelhantes, Paiva (2010) 
e Freitas (2012). Leitura sobre as características locais geoambientais, socioeconômicas e políticas sobre a cidade de Sobral, além de trabalhos sobre aspectos da dinâmica atmosférica, clima urbano, característica climáticas local/regional.

O levantamento cartográfico foi realizado com apoio de geotecnologias, a utilização de imagens de satélites, auxiliaram na definição dos pontos para coleta de dados. Somado a isso o conhecimento e vivência do autor em relação à área de estudo, o Centro da cidade. Desta forma, foram estabelecidos pontos heterogêneos no que se refere às características de uso e ocupação do solo, representativos da diversidade urbana da cidade de Sobral (CE).

Assim, após análise cartográfica, trabalhos de campo preliminares e a determinação técnico-metodológica, determinou-se os postos de coleta de dados (PCD), onde foram mensuradas as condições microclimáticas do centro da cidade de Sobral em quatro pontos distintos em relação às dinâmicas urbanas.

A escolha dos PCD`s foi realizada a partir da distinção entre os ambientes representativos da diversidade urbana da área central, sendo: uma área comercial totalmente pavimentada e sem arborização (PCD 01); em contraste com uma outra área com maior arborização (PCD 02); uma faixa urbanizada da margem do rio Acaraú (PCD 03); e uma área que tem sofrido recentes modificações na paisagem com a chegada de novo instrumento social, um campus da Universidade Federal do Ceará - UFC (PCD 04).

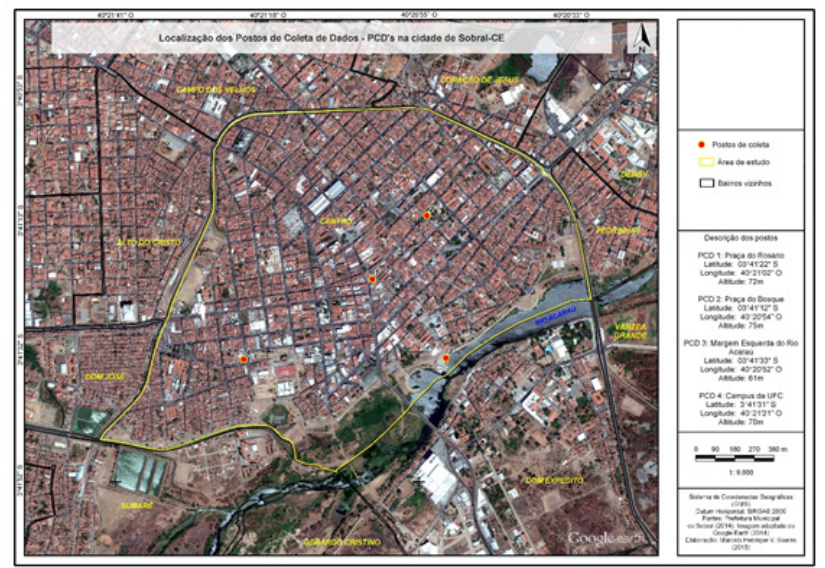

Figura 04 - Localização dos Postos de coletas de dados Fonte: Acervo particular dos autores (Fevereiro de 2016)

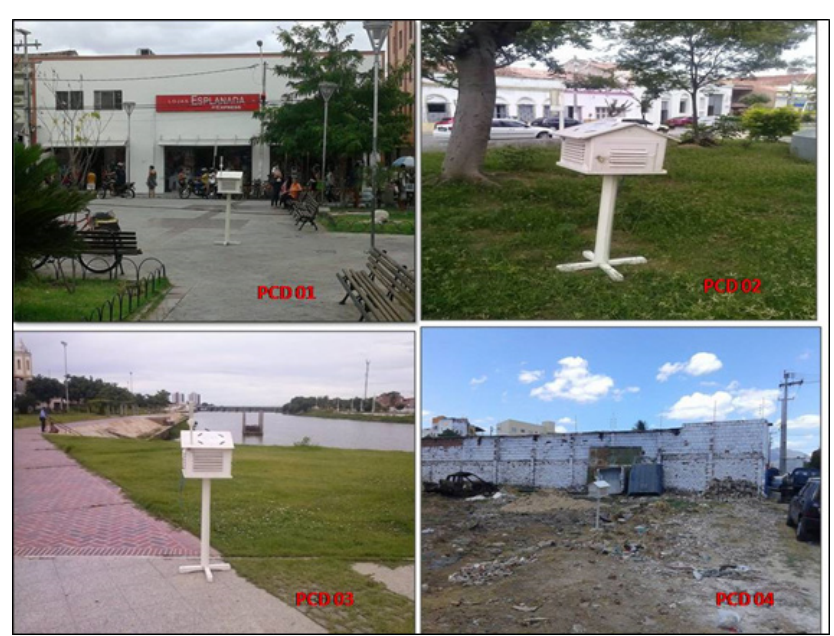

Figura 05 - Vista dos Postos de coletas de dados Fonte: Acervo particular dos autores (Fevereiro de 2016)

Conforme as figuras 04 e 05, o Posto de Coleta Dados (PCD) 01 diz respeito à Praça do Rosário (coordenadas E: 349971e N: 9592044); o PCD 02 deu-se na Praça do Bosque como é popularmente conhecida a Praça Duque de Caxias (coordenada E: 350218 e N: 9592352); o PCD 03 foi instalado na denominada "Margem Esquerda" do Rio Acaraú (E: 350280 e N: 9591707); e o PCD 04 no recém-criado Campus da UFC (coordenada E: 349355 e N: 9591675).

As coletas de dados foram divididas em duas etapas representantes da sazonalidade do clima regional semiárido. A etapa I (Primeiro Experimento) de coleta de dados foi realizada no dia 28/04/2014, equivalente ao outono austral (estação chuvosa) e a etapa II (Segundo Experimento) aconteceu no dia 06/11/2014, no período de estação seca correspondente à primavera meridional.

As coletas ocorreram simultaneamente nos quatros PCD's nos horários de 6, 9, 12, 15 e 18 horas. Os horários foram estabelecidos após várias leituras e constatando que são os mais utilizados, pois segundo Viana (2006), citado por Freitas (2012), são os horários mais significantes para observações das variações do tempo atmosférico no passar do dia, em condições atmosféricas estáveis.

Às 6h, há o final da madrugada e o início do aquecimento diurno. Às 9h inicia-se o período de maior aquecimento diurno, que atinge a magnitude entre as $15 \mathrm{~h}$ e $16 \mathrm{~h}$, por conta da máxima emissão de radiação terrestre para a atmosfera [...] Dessa forma, no final de cada observação ficam registradas as características climáticas de cada período, necessárias para a compreensão de como o uso e ocupação do solo interferem na distribuição espacial térmica e higrométrica do ar intra-urbano e rural (FREITAS, 2012, p .44). 
Foram coletados dados de temperatura (ambiente, máxima e mínima), de umidade, pluviosidade e ventos. O termômetro utilizado possibilita a coleta de dados de temperatura mínima e máxima e ainda a temperatura momentânea. Sua importância está na verificação da amplitude térmica diária, podendo verificar-se as possíveis condições de calor ao longo do dia relacionadas à sensação térmica.

Para a mensuração da umidade, utilizamos o termohigrômetro analógico, que registra tanto os valores da umidade os de temperatura.

Para obtenção dos dados da velocidade do vento utilizamos o anemômetro digital. Para verificação da direção do vento foram instaladas fitas $n^{\circ} 1 \mathrm{com}$ tamanho de $25 \mathrm{~cm}$ na base de sustentação do abrigo meteorológico, a observação foi baseada nos pontos cardeais e colaterais na própria base de sustentação, após observar a direção posicionava-se o anemômetro para medir a velocidade do vento.

O pluviômetro foi empregado para a mensura das precipitações, a variável fornecida refere-se aos acumulados pluviométricos, relativos a um determinado período de tempo. Uma vez instalado no abrigo, numa haste acoplada no lado esquerdo superior do abrigo meteorológico, a abertura de captação do pluviômetro ficou situada a $2 \mathrm{~m}$ do solo.

De posse dos dados e tendo elaborado os gráficos de temperatura e umidade, os resultados foram correlacionados e alocados no diagrama do conforto térmico humano utilizado pelo INMET que estabelece a zona de conforto a partir do cruzamento da temperatura do ar com a umidade relativa, gerando assim outras sete zonas, sendo elas: muito quente, muito úmido, muito frio, muito seco, necessita de vento para conforto, necessita de sol para conforto e confortável.

Além dados obtidos em campos, foram coletados as informações com os mesmo parâmetros climáticos, no site do INMET (resultados oficiais para a cidade de Sobral) referentes aos dias que foram realizadas as coletas dos dados em campo, no intuito de compará-los, afinal os resultados oficiais da estação meteorológica, são mensuradas em uma área afastada da urbanização da cidade.

O trabalho de campo também precisa ser completado pela observação dos sistemas atmosféricos atuantes, tanto no dia anterior quanto no dia da coleta de dados. Esses dados são fundamentais para a compreensão do tempo atmosférico.

\section{RESULTADOS E DISCUSSÕES}

Para se entender com maior precisão os resultados obtidos nessa pesquisa é importante ressaltar a atuação do El Niño-Oscilação Sul (ENOS) interferindo, sobretudo, na precipitação do Nordeste brasileiro (NEB), o qual repercutiu ao longo de todo o ano estudado (2014), diminuindo a intensidade das chuvas produzidas pela ZCIT no primeiro semestre (estação chuvosa) e acentuando a estiagem do segundo semestre (estação seca).

Dentre de tais condições climáticas regionais é que foram executados os experimentos e produzidos os resultados e análises locais a seguir.

\subsection{Análises do Primeiro Experimento (28/04/2014) - Outono Austral:}

A ZCIT teve participação decisiva nos resultados do período chuvoso, pois, apesar de não ter havido precipitação no dia da coleta dados, influenciou diretamente a umidade relativa do ar e na grande quantidade de nuvens para o dia, o que diminuiu a intensidade dos raios solares na superfície da área em estudo.

Através da correlação dos dados, percebemos que, apesar das altas temperaturas os demais atributos climáticos, associados à atuação da ZCIT, produz um diagrama do conforto térmico expondo situações não tão adversas microclimaticamente para a população que mora e/ou visita esta região do centro da cidade de Sobral.

Às 6 horas, momento em que o sol acabou de surgir no horizonte da cidade de Sobral, o resultado nos mostra que as condições térmicas para o horário apresentam uma área de transição entre o CONFORTÁVEL e MUITO ÚMIDO, visto que o valor da umidade variou entre $78 \%$ (PCD 01) a 84\%(PCD 03) e com temperaturas variando de $24^{\circ} \mathrm{C}$ a $26^{\circ} \mathrm{C}$, entretanto, essa alta umidade não vai expor a sensação de saturação, "abafado", devido à temperatura ainda estar com valores na faixa do “confortável" segundo o diagrama. Já os ventos numa calmaria, registrou valor máximo de $1,9 \mathrm{~m} / \mathrm{s}$ no PCD 03 , estabelecendo assim uma brisa leve e constante no local; e valor mínimo de $0,1 \mathrm{~m} / \mathrm{s}$ no PCD 01, uma aragem, segundo a escala de Beaufort.

As 09:00 horas, com exceção do PCD 03 que se estabeleceu na zona do CONFORTÁVEL, todos os demais pontos registraram seus dados na zona do NECESSITA DE VENTO PARA CONFORTO, assim os ventos têm papel crucial. 


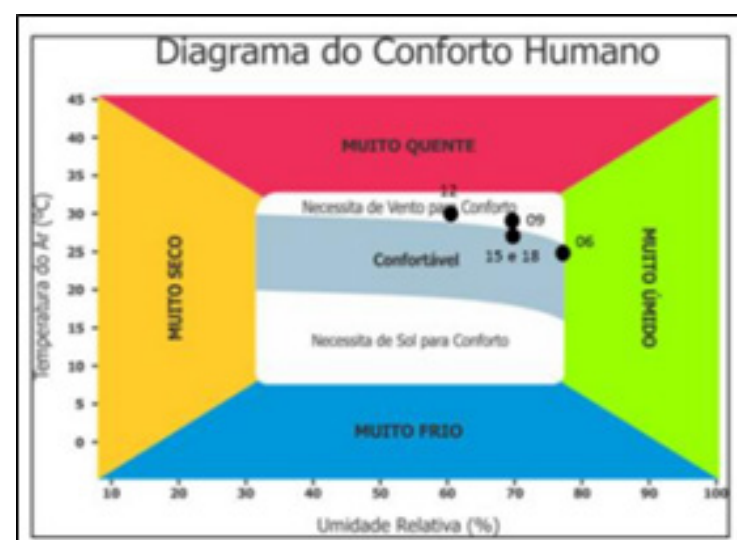

PCD 01

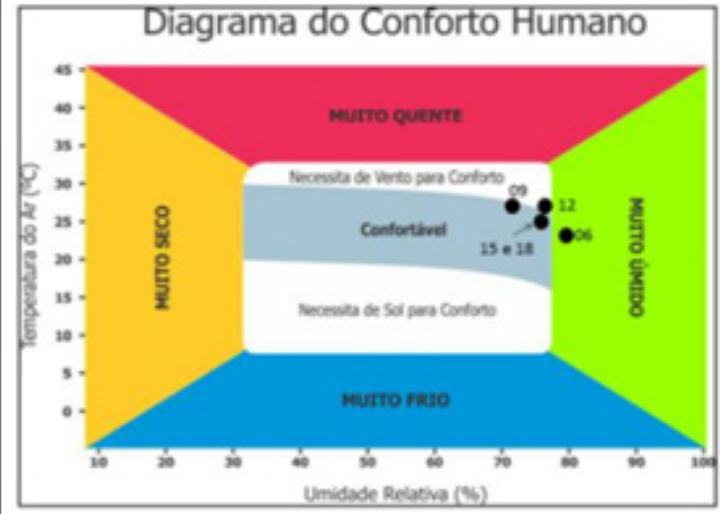

PCD 03

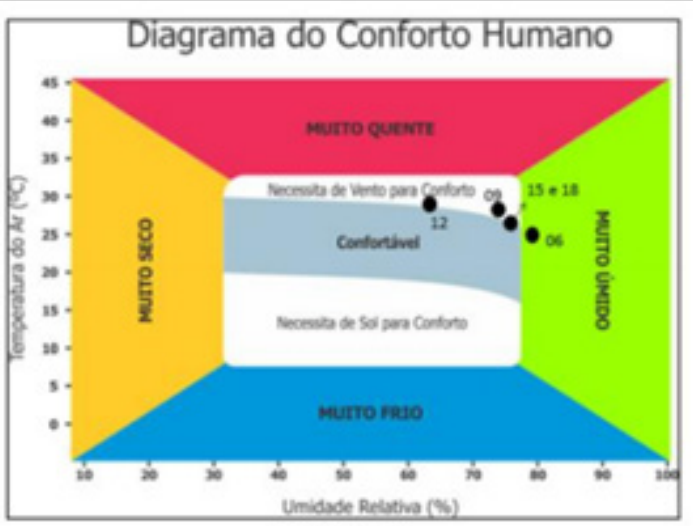

PCD 02

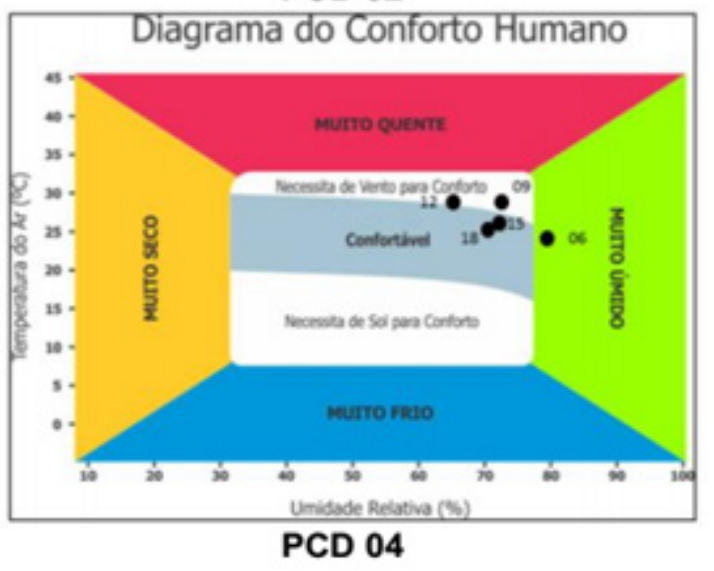

Figura 06 - Diagrama do Conforto Humano para PCD 04 Fonte: Fonte: Adaptado INMET, 2013

No entanto o PDC 01 registrou para horário apenas $0,7 \mathrm{~m} / \mathrm{s}$ e inconstante, desta forma o conforto térmico é sentido quando há picos de ventos no local.

No horário de meio dia obtivemos a maior temperatura e menor valor de umidade na média e em valores absolutos no PCD 01 , apresentando $30^{\circ} \mathrm{C}$ e $62 \%$ respectivamente. Correlacionando a temperatura e umidade relativa do ar, todos PCD's marcaram na zona de NECESSITA DE VENTO PARA CONFORTO. Havendo para horário destaque na nebulosidade com 6 ou $7 / 8$ partes para horário. As condições microclimáticas geram desconforto térmico com a ausência dos ventos, perceptível sobretudo no PCD 01.

Nas coletas seguintes as 15 e 18 horas, os dados se assemelharam, inclusive a correlação da temperatura e umidade foram as mesmas no PCD 01, PCD 02 e PCD 03, fixando-se na zona do CONFORTÁVEL: temperatura entre $25^{\circ} \mathrm{C}$ e $27^{\circ} \mathrm{C}$ e umidade relativa do ar, variando entre $70 \%$ e $78 \%$. É válido ressaltar a ausência de ventos na última coleta, havendo registro apenas nos PCD
01 e PCD 03, sendo respectivamente $0,1 \mathrm{~m} / \mathrm{s}$ e $0,3 \mathrm{~m} / \mathrm{s}$. Fato que provoca variações nas percepções dos transeuntes de acordo com a paisagem de cada PCD.

\subsection{Análises do Segundo Experimento (06/11/2014) - Primavera Meridional}

Naturalmente, os ambientes tropicais podem gerar certo desconforto térmico pela grande quantidade de calor que é intensificada com o crescimento territorial das áreas urbanas, mas essa condição se agrava quando não se atenta para as características climáticas no processo de planejamento urbano.

A ausência de sistemas de nuvens atuando diretamente na escala local, proporcionou estabilidade atmosférica e com exceção das 9 horas, o dia foi marcado por intensa insolação, típico do período seco do semiárido brasileiro, acentuando as altas temperaturas. Por isso, é imprescindível a manutenção de atributos, como a vegetação e a conservação dos recursos hídricos, que possam amenizar o forte calor e que gerem condições ambientais de conforto térmico humano. 


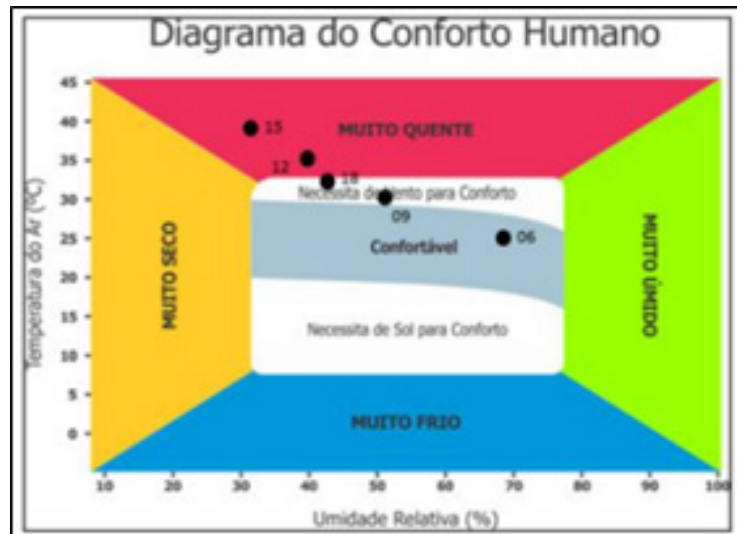

PCD 01

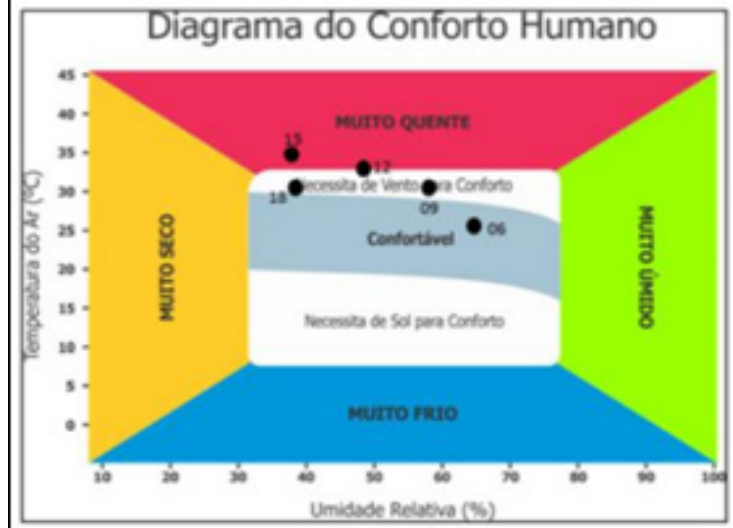

PCD 03

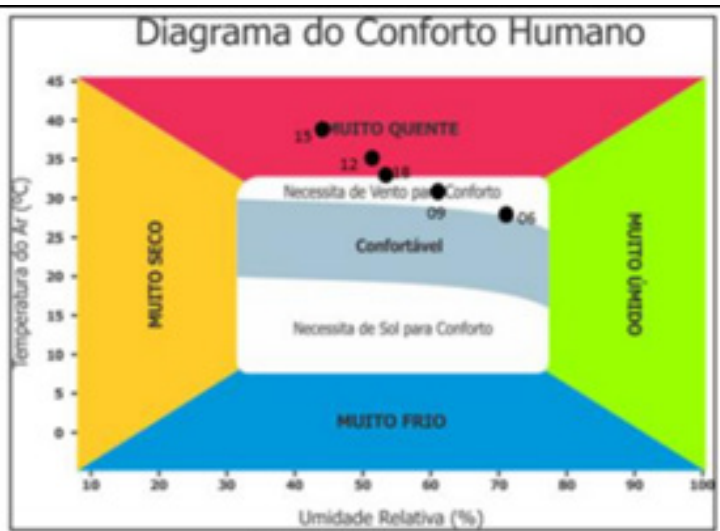

PCD 02

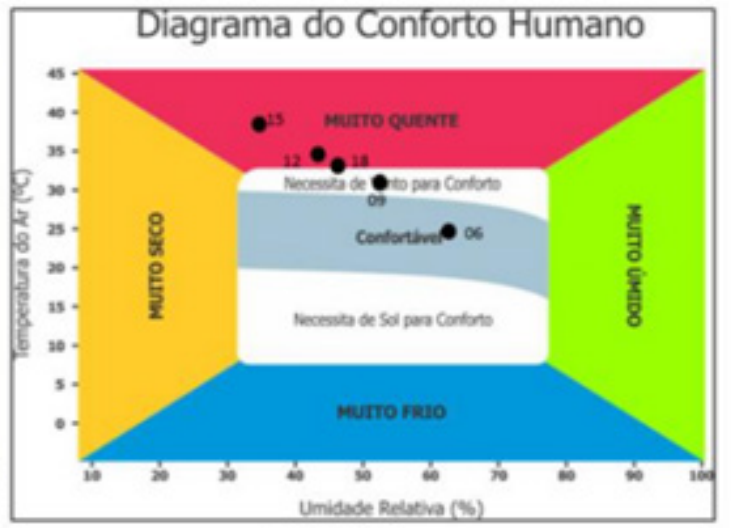

PCD 04

Figura 07- Diagrama do Conforto Humano para PCD 04 Fonte: Adaptado INMET, 2013

O contraste térmico da sazonalidade fica explícito na amplitude térmica sazonal, enquanto para o mês de abril a temperatura máxima foi de $31^{\circ} \mathrm{C}$, no mês de novembro atingiu $39,5^{\circ} \mathrm{C}$. Situação que se repete na temperatura mínima e umidade relativa do ar. Diferente do observado no período chuvoso a zona do CONFORTÁVEL só é identificado na primeira hora de coleta nos quatros PCD's; às 06 horas, apesar dos PCD's terem registrados temperaturas favoráveis

ao conforto térmico, houve uma amplitude térmica de $3^{\circ} \mathrm{C}$ entre o PCD 02 e PCD 03, apresentando respectivamente $27^{\circ} \mathrm{C}$ e $24^{\circ} \mathrm{C}$, e demais PCD's $25^{\circ} \mathrm{C}$. Já a umidade relativa do ar, apresentou variações entre $63 \%$ e $72 \%$.

Às 09 horas houve uma forte nebulosidade registrada em todos os PCD's, talvez o principal fator de manutenção da umidade relativa do ar ainda acima dos $50 \%$, porém com as temperaturas atingindo entre $30^{\circ} \mathrm{C}$ e $32^{\circ} \mathrm{C}$, os valores analisados, segundo o diagrama conforto térmico, ficaram estabelecidos na zona de NECESSITA DE VENTO PARA CONFORTO.

Ventos estes que registraram 2,9 m/s, 3,9 m/s, 2,5 $\mathrm{m} / \mathrm{s}$, e $5,1 \mathrm{~m} / \mathrm{s}$, respectivamente nos PCD 01, 02, 03 e 04 .
Esses valores poderiam significar uma amortização da temperatura, porém, a inconstância dos mesmos não garante situações de conforto, pois isso depende também de sua intensidade e modificações de direção. E para os que vivenciam os locais, neste horário uma sombra é muito útil para amenizar a alta insolação, já que são raras devido à ausência da vegetação arbórea. A exceção é o PCD 03, por está situado no leito do Rio Acaraú, canal de ventos para cidade, nesse ponto a ventilação é contínua.

Ao meio dia a composição das nuvens muda drasticamente, e temos um céu quase que totalmente limpo, com tempo seco (umidade de 40\% no PCD 01), além de uma forte radiação, traduzindo-se numa temperatura do ar de $35^{\circ} \mathrm{C}$ nos PCD 01 e PCD 02 , e $35,5^{\circ} \mathrm{C}$ no PCD 04, bem acima dos ideais, segundo a Organização Mundial Meteorológica (OMM) para a saúde humana e dentro do diagrama do conforto térmico, a associação desses atributos do clima se fixou na faixa do MUITO QUENTE, onde, de fato, percebe-se um ambiente com muito calor e sente-se bastante desconforto, tornando fatigante até efetuar uma simples caminhada.

$\mathrm{E}$ o vento que poderia ser um aliado, nesse período aumenta a sensação de calor, pois com o tempo seco, o vento 
que soprou de 1,5 m/s no PCD 01 a 5,9 m/s no PCD 04, aviva o calor (vento quente) e "secura" sentida pela população através da pele e da irritação nas vias respiratórias.

Novamente o PCD 03 apresenta resultados menos agressivos em relação ao conforto térmico, com temperatura de $33^{\circ} \mathrm{C}$ e Umidade relativa do ar de $52 \%$, no entanto, esses valores correlacionados no diagrama, fixam-se numa faixa de transição do NECESSITA DE VENTO PARA O CONFORTO e a ZONA MUITO QUENTE.

Ás 15 horas foram assinaladas as maiores temperaturas nos PCD's, atingindo os $38^{\circ} \mathrm{C}$, com exceção do PCD 03 que assinalou $35^{\circ} \mathrm{C}$, mesmo assim, todos foram níveis danosos à saúde humana e, novamente com céu quase totalmente limpo, observamos um tempo bastante seco com umidade de apenas $32 \%$ no PCD 01, a menor registrada nos dois experimentos.

Deste modo, de acordo com diagrama do $\mathrm{IN}$ MET, todos ao PCD'S estão inseridos na faixa do MUITO QUENTE e, outra vez, a atuação dos ventos age de forma negativa para a população devido aos valores de temperatura e umidade. Essa foi a situação mais adversa em relação ao conforto térmico da pesquisa.

A queda da temperatura observada às 18 horas associada ao aumento da umidade relativa do ar, ofereceu uma pequena melhora à situação do conforto térmico. Pequena mesmo, pois os $33^{\circ} \mathrm{C}$ de temperatura registrados (nos PCD's 01,02 e 04) é justamente o limite considerado adequado para o ser humano e desta forma a faixa fixada para o horário foi MUITO QUENTE, porém em transição com o NECESSITA DE VENTO PARA CONFORTO. No PCD 03 apresentou seus valores totalmente na faixa do NECESSITA DE VENTO PARA CONFORTO. Ressaltamos que, para o horário em questão, a radiação não influencia tanto e a intensidade da brisa aumenta nestes locais, gerando sensações de alívio às altas temperaturas diurnas e a percepção dos moradores e transeuntes tendem a um maior conforto térmico ao passar das horas noturnas.

\section{CONSIDERAÇÕES FINAIS}

Por meio da análise dos atributos (micro)climáticos do centro da cidade de Sobral (CE), observou-se que as altas temperaturas é uma constante em seu contexto urbano, expressando localmente uma das principais características do semiárido nordestino. Contudo, essa característica regional tem se acentuado pelas variáveis climáticas locais associadas à conjuntura do espaço urbano (morfologia, sítio e função urbana), algo que é evi- dente quando confrontamos os dados de campo com os registros oficiais da Estação Meteorológica do INMET localizada fora da área urbana e onde os registros dos parâmetros climáticos estudados tendem sempre a uma condição de menor desconforto térmico, salientando a influência da atuação do El Niño no comportamento dos parâmetros climáticos no período considerado.

Os resultados obtidos nos PCD's revelaram que a sazonalidade exerce grande efeito no conforto térmico, pois no $1^{\circ}$ Experimento, no mês abril, período chuvoso da região, houve situações positivas de conforto térmico para todos os postos, chegando inclusive, a registrar em três dos cincos horários valores dentro da faixa do "confortável" na Margem Esquerda do Rio Acaraú, e não houve situação na faixa de "muito quente" para este experimento.

Ao encerrar o balanço do conforto térmico, fica expresso que os condicionantes socioambientais têm contribuído ativamente para a formação de um microclima local, agindo em grande parte na geração de um desconforto térmico, tanto que os resultados mostraram três situações na faixa do MUITO QUENTE e apenas uma no CONFORTÁVEL, nos PCD 01e PCD 04.

Indiscutivelmente as transformações ocorridas na cidade de Sobral, principalmente nas duas últimas décadas, têm gerado a produção de um clima urbano que vem se alterando em escala microclimática de forma diferenciada e perceptiva às sensações humanas. As alterações nas condições atmosféricas locais são mais perceptíveis ao longo do bairro central da cidade, onde áreas com características socioambientais semelhantes têm propiciado a formação de microclimas distintos e, na grande parte do ano são sentidas pela população por serem geradoras de desconforto térmico.

\section{REFERÊNCIAS}

AYOADE, J.O. Introdução à Climatologia para os Trópicos. 12 ed. Rio de Janeiro: Bertrand Brasil, 2007.

CARACRISTI, I. A Climatologia: Domínios e Métodos. Jornal Espaço-Tempo, v.1, n.1. Sobral/CE, 1996.

CARACRISTI, I. Estudo Integrado do Clima da Região do Médio Curso do Rio Acaraú: uma análise geográfica do clima local. Revista Essentia, v.1, n.1, 2000. 
FREITAS, R. Entre Mitos e Limites: As possibilidades do adensamento construtivo face à qualidade de vida no ambiente Urbano. 2005. 271p. Tese (Curso de Doutorado em Arquitetura) - Universidade Federal do Rio Grande do Sul, Porto Alegre.

FROTA, A.B.; SCHIFFER, S.R. Manual do conforto térmico. São Paulo: Nobel, 1988.

FUNDAÇÃO CEARENSE DE METEOROLOGIA E RECURSOS HÍDRICOS - FUNCEME. Sistemas meteorológicos causadores de chuvas na região nordeste do Brasil. Boletim especial, 2002.

GOVERNO DO ESTADO. INSTITUTO DE PESQUISA E DE ESTRATÉGIA ECONÔMICA DO CEARÁ - IPECE. Perfil Básico Municipal de Sobral. Fortaleza, 2010 .

HOLANDA, V.C.C. de; AMORA, Z.B. (Org.). Leituras e saberes sobre o urbano: Cidades do Ceará e Mossoró no Rio Grande do Norte. Fortaleza: Expressão Gráfica, 2010 .

HOLANDA, V.C.C. de. Modernizações e espaços seletivos no Nordeste brasileiro. Sobral: Conexão Lugar/ Mundo. 2005. 254p.Tese (Doutorado em Geografia Humana) - Universidade de São Paulo, São Paulo.

HOLANDA, V.C.C. de. Sobral - CE: de cidade do sertão às dinâmicas territoriais da cidade média do presente. In: VIRGINIA, C.H.A.; ZENILDE, B. (Org.). Leituras e Saberes Sobre o Urbano: cidades do Ceará e Mossoró no Rio Grande do Norte. 1 ed. Fortaleza: Expressão Gráfica e Editora, 2010. p. 75-94.

INSTITUTO NACIONAL DE METEOROLOGIA INMET. Diagrama do conforto humano. Disponível em: www.inmet.gov.br. Acesso em: 10 abr. 2014.

LIMA, J.G. Dinâmicas urbanas em espaços sertanejos cearenses: novas configurações do urbano e ações imobiliárias em Sobral/CE. 2014. 167f. Dissertação (Mestrado Geografia) - Universidade Estadual Vale do Acaraú, Sobral.

MAIA JÚNIOR, L.P. Estudo dos Impactos do Desmatamento Sobre os Microclimas da Microbacia do Riacho do Boqueirão (Sobral - CE). 2011. 126f. Disser- tação (Mestrado em Geografia) - Universidade Estadual do Ceará, Fortaleza.

MENDONÇA, F; DANNI-OLIVEIRA, I. M. Climatologia: noções básicas e climas do Brasil. São Paulo: Oficina de Texto, 2007.

MENDONÇA, F. Clima e Planejamento Urbano em Londrina: proposição metodológica e de intervenção urbana a partir do estudo do campo termo-higrométrico. In: MONTEIRO, C.A.F.; MENDONÇA, F. (Org.). Clima urbano. São Paulo: Contexto, 2003.

MONTEIRO, C.A. de F. Teoria e Clima Urbano. Série Teses e Monografias n. 25. São Paulo: Instituto de Geografia/USP, 1976.

MONTEIRO, C.A. de F. A cidade como processo derivador ambiental e a geração de um clima urbano: estratégias na abordagem geográfica. Revista Geosul, v. 5, n. 9, p. 80-114, 1990. Disponível em: https://periodicos.ufsc.br/ index.php/geosul/issue/view/1222. Acesso em: 22 out. 2014.

MONTEIRO, C.A. de F. Adentrar a cidade para tomar-lhe a temperatura. Revista Geosul, v. 5, n. 9, p. 61-79, 1990. Disponível em: https:/ / periodicos.ufsc.br/index.php/geosul/issue/view/1222. Acesso em: 22 out. 2014.

MONTEIRO, C.A. de F. Cidade e Ambiente Atmosférico. Revista Geosul, v. 5, n. 9, p. 115-123, 1990. Disponível em: https://periodicos.ufsc.br/index.php/geosul/issue/ view/1222. Acesso em: 22 out. 2014.

MONTEIRO, C.A. de F. Por um suporte teórico e prático para estimular estudos geográficos de clima urbano no Brasil. Revista Geosul, v. 5, n. 9, p. 7-19, 1990. Disponível em: https://periodicos.ufsc.br/index.php/geosul/issue/ view/1222. Acesso em: 22 out. 2014.

MONTEIRO, C.A.F; MENDONÇA, F. (Orgs.). Clima Urbano. São Paulo: Contexto, 2003.

MUNIZ, F.G.L. Urbanização e Conforto Térmico: Análise Climática do Centro da Cidade de Sobral CE. 2016. 226f. Dissertação (Mestrado em Geografia) Universidade Estadual Vale do Acaraú, Sobral. 
PAIVA, J.P.M. Análise microclimática em conjuntos habitacionais: o caso do Conjunto Ceará - Fortaleza/ CE. 2010. 142p. Dissertação (Mestrado em Geografia) Universidade Estadual do Ceará, 2010.

SANT'ANNA NETO, J.L. Clima e organização do espaço. Maringá: Boletim de Geografia da UEM, 1998.

SOBRAL. Lei Orgânica Municipal de Sobral, 1990. Disponível em: http://www.sobral.ce.gov.br/. Acesso em: 15 jan. 2015.

SOBRAL. Lei de Parcelamento, Uso e Ocupação do Solo, 2008. Disponível em: http://www.sobral.ce.gov.br/. Acesso em: 15 jan. 2015.

SOBRAL. Plano de Desenvolvimento Urbano de Sobral, 2008/2010. Disponível em: http://www.sobral.ce. gov.br/. Acesso em: 15 jan. 2015.

SANCHEZ, F. A reinvenção das cidades para um mercado mundial. Chapecó: Argos Editora Universitária, 2003.

SORRE, M. Objeto e método da Climatologia. Tradução de José Bueno Conti. Revista do departamento de Geografia, n. 18, p. 89-94, 2006. Disponível em: http:// www.geografia.fflch.usp.br/publicacoes/rdg/RDG_18/ RDG18_089_o94.pdf. Acesso em: 15 nov. 2012.

\section{Correspondência dos autores:}

Francisco Gerson Lima Muniz

e-mail: gersongeo@hotmail.com

Isorlanda Caracristi

e-mail: icaracristi@hotmail.com

Artigo recebido em: 16/08/2017

Revisado pelos autores em: 05/03/2018

Aceito para publicação em: 15/03/2018 